\title{
Theoretical Evaluation of Moment Resistance for Bolted Timber Connections
}

\author{
Junting Guo ${ }^{1, a}$ and Zhan Shu \\ ${ }^{1}$ The College of Architecture, Washington University in St.Louis, Brookings,DR, Campus Box 1083, Saint Louis, MO 63130,US \\ 2 Department of Civil Engineering, Shanghai University, Shanghai 200444, China
}

\begin{abstract}
Timber construction is nowadays becoming more and more favorable due to multiple advantages. In this paper, the connection type and material of timber building were first highlighted. Then, the bolted joints with slotted-in steel plates were systematically tested and analyzed. A typical slotted-in bolted glulam connection was simulated using the software Abaqus. Furthermore, a few important design variables were measured and used to numerically estimate the embedment strength, the shear force per plane, and the ultimate moment capacity of the connections. At last, multiple configurations of joint design were compared in the paper, and a parametric design was made. The results were systematically explained.
\end{abstract}

\section{Introduction}

Wood is a traditional construction material that has been widely used along with human civilization. Considering sustainable development, wood could become a renewable and environmentally friendly construction material when the forest resource is properly arranged [1]. Most of the current construction materials such as concrete and steel produce massive dust and various wastes during construction. Considering such an escalated environmental problem, timber-made structures become a more favorable choice in the field of civil engineering.

Besides, timber structures have many other advantages other than their environmentally friendly attributes. (1) Living in a timber structure makes people feel themselves closer to nature, therefore brings comfort and reduces pressure. (2) Raising up a timber frame is a quick process. A timber frame can be erected on site faster than a comparable steel or cement construction [2]. (3) As human labor is required less in timber construction, the general construction costs also decrease. According to the UK Timber Frame Association, labor requirements for timber type of construction can lower labor needs by 20 percent. Building a timber frame home will range in cost from $\$ 150$ to $\$ 175$ per square foot for basic designs [3]. In addition, rehabilitation and repairing techniques of timber structures involving structural adhesives has proved to be both structurally efficient and economically competitive when compared with alternative repair procedures [5].

Common wood structures include light-frame wood structure, post-and-beam timber frame structure, space wood structure, cross laminated wood timber structure and timber hybrid structures. Light-frame wood construction, using smaller members spaced closely together in load sharing arrangements, offers economy, strength, and flexibility that can be applied to not only residential houses but also large commercial buildings. Post-and-beam timber frame structures are widely used in commercial and public buildings as the large space between their beams and columns provides flexible space to use.

In addition, modern timber frame structure could be categorized to timber frame bracing structure and timber frame shear wall structure. The vertical load is mainly supported by beam-column elements, while the horizontal load is mainly supported by supporting shear wall and other lateral elements. With the aid of modern technology, taller timber structures become possible. The Canadians used to hold the world's record for the tallest residential timber tower. The Commons Tallwood House (shown in Figure 1) is 164 feet tall. The structure is a student residence, topped out in the year of 2017 at the University of British Columbia (UBC), in Vancouver. The current tallest timber structure stands in Norway, named Mjøstårnet. It was designed by Norwegian practice Voll Arkitekter. The 18 -story mixed-use building contains apartments, hotel, swimming pool, office space, and a restaurant, shown in Figure 2 [3]. In addition, a Tokyo skyscraper is set to become the world's tallest wooden building in the future [3].

The increasing height of timber structure cannot leave without materials. Glu-laminated timber (Glulam), cross-laminated timber (CLT), Laminated Veneer Lumber

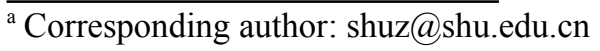


(LVL), parallel strand 1umber (PSL) are some of the modern timber materials over the world that were developed based on the newest technologies.

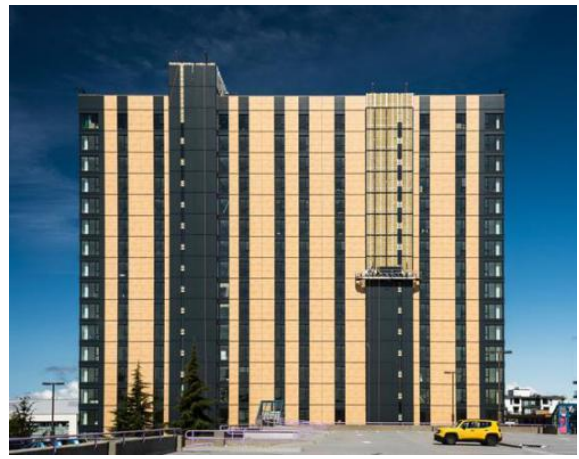

Figure 1. UBC residential timber building,

Vancouver, Canada, 53 METRES [6].

(shown in Figure 4). Glulam, which is the most commonly used material currently, has a high strength-to-weight ratio. Its shape can be changed into long a span bending form available for the construction of indoor stadiums. Better yet more expensive materials, such as PSL were made of strands that were clipped-veneer elements having a minimum dimension of 0.25 inches and an average length of at least 300 times this least dimension. The Douglas-fir, southern pine, western hemlock, and yellow-poplar are commonly chosen for PSL because of their superior strength [7]. Studies have shown that the tensile strength of timber is much higher than that of concrete, which proves the strength and superiority of timber material [21]. Furthermore, along with the invention of new timber materials, the likelihood of the inflammability of timber is also significantly reduced. These large modern timbers covered with unburnt varnish. Even if the fire accidentally appears, a few centimeters of unburnt char will form, which protects the timber inside (shown in Figure 3). Failure of the beam or struct will occur only when the cross-sectional area of the unburnt core becomes too small to support the load [8]. Modern technologies also provide solutions against termite, moisture, and temperature changes to timber materials. Timber-made homes could last two to three times as long as the standard modern home, which

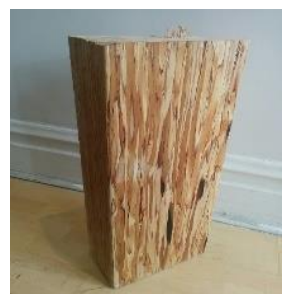

(a)

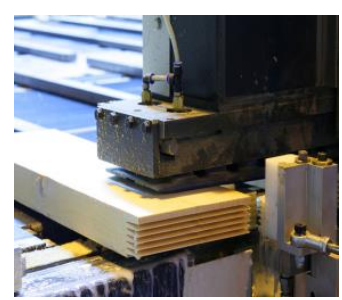

(b)

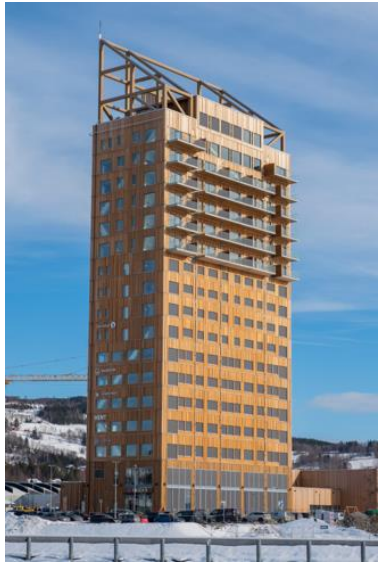

Figure 2. Tallest timber structure, Mjøstårnet, Norway [4].

lasts for about 100 years [7].

Moreover, the connection part is crucial for timber structures. The strength of the connection is highly relevant to the overall performance of the whole timber structure. Different connections could be selected for different timber structures. For tall structures, the connections are desired to be stiff enough to hold the strong winds and/or earthquakes. For many traditional timber buildings in China and the Middle East, mortise and tenon connection is the common type. The tenon, formed on the end of a member generally referred to as a rail, fits into a square or rectangular hole cut into the other, corresponding member [14]. In modern connections, fasteners are also commonly used as they could increase the strength of the connections. When fasteners have plastic deformation, ductile performance occurs. In dowel-type fasteners (e.g. nails, screws, dowels and bolts), ductility is achieved by means of the plastic deformation in metallic connectors [13].

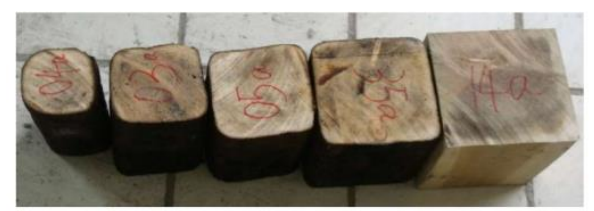

Figure 3. Unburnt portion of timber.

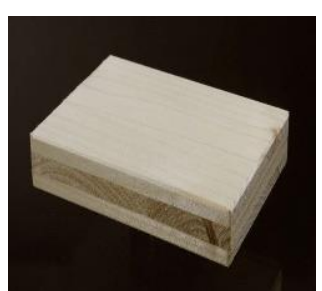

(c)

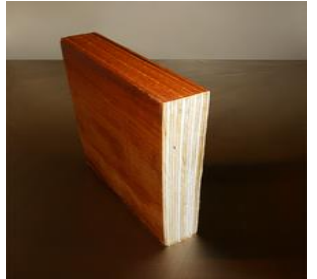

(d)

Figure 4. Different timber materials, (a)PSL [9]; (b) Glulam [10]; (c) CLT [11]; (d) LVL [12].. 


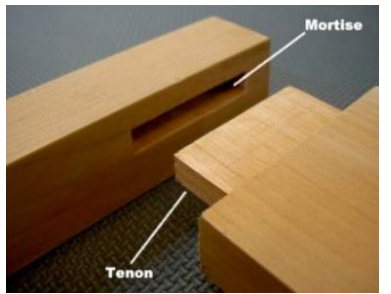

(a)

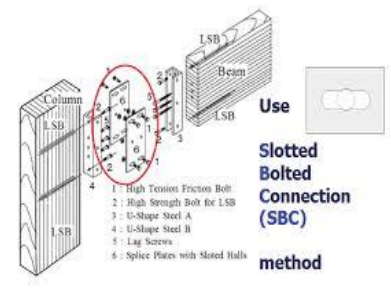

(b)
Figure 5. Existing timber connections (a) Mortise and Tenon connection [15]; (b) Slotted Bolted Connection [16].

In the current prevalent laminated timber beam-column system, the laminated timber beams and columns are often connected by slotted-in bolted joints, which is the type of connection presented in this study. The slotted-in bolted joints with steel plate connection has high resistance to horizontal load, but earthquakes usually push the building in the horizontal direction, adding demand of the moment resistance of such connections. Typical pinching phenomena can be observed in the hysteresis behavior of nailed connections in walls, and in nailed frames, while stable dissipating hysteresis loops and limited stiffness degradation can be found with glulam connections proposed by Buchanan and Fairweather [17] [18]. The beam-column joints are the weak part of the structure due to the gap between the reserved holes and bolts of this kind of joints, which is mainly manifested in the yield of metal joints and the plastic deformation of wood. Nonetheless, unlike steel or reinforced concrete joints whose moment resisting capacities could be directly hand calculated, glulam bolted connections have not got a reliable and direct method to obtain their mechanical properties. To do mathematical analysis for timber slotted-in bolt joints timber connection, the main components that need to be considered include the material itself, steel plates, and the fasteners connecting the timber members [19-22]

This study focuses on the moment resistance for bolted timber connections. Joints with larger fastener sizes (i.e., diameters of $20 \mathrm{~mm}$ or more), which are more commonly used sizes, were selected. Associated with these conditions, the brittle performance of wood was expected, which was proved from multiple sets of experimental results. Finite element model was established to evaluate the rotational performance of such joints. A series of estimation formulas were adopted from an existing study, which could provide estimations for the moment capacity, coupled shear and
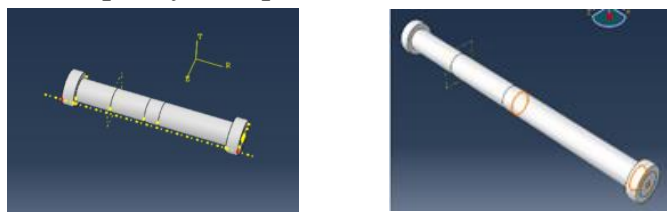

(a)

(b) rotational strength. The obtained results include multiple design configurations that were systematically analyzed. At last, a parametric design was created based on the hand calculation model.

\section{Finite element analysis model with Abaqus}

\subsection{Finite element analysis}

This study provides a comprehensive study of the rotational performance of glulam bolted joints. A finite element model was made in Abaqus, and hand calculation model was performed in Matlab. A comparison between the Abaqus model and hand-calculation model was made. The finite element method (FEM), is a numerical method for solving problems of engineering and mathematical physics. Typical problem areas of interest include structural analysis, heat transfer, fluid flow, mass transport, and electromagnetic potential. The analytical solution of these problems generally requires the solution to boundary value problems for partial differential equations. The finite element method formulation of the problem results in a system of algebraic equations. The method approximates the unknown function over the domain [23]. In the software Abaqus, it uses FEM as the basis of creating the model and simulating the deformation of the model relating to the force on it.

The FEM model could also be used to provide estimations of the rotational strength for different designs of the bolted timber joints. The contact surface between the nut and the wood was slightly increased as the washers were not included in the model. Friction contact was not defined in the model. Hard contacts were defined between the bolts and the steel holes. All the other contacts were soft contacts, setting the surfaces of the steel elements as main surfaces and the surfaces of the wood elements as the slave surfaces.

\subsection{Test setup \& model design}

The model is a joint of a post $\&$ beam timber structure, which is a prototype slotted-in steel plate bolted timber joint. This model is an assembly of several components, shown in Figure 6:

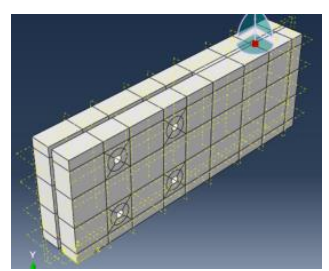

(c) 


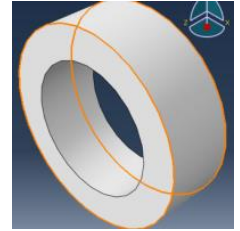

(d)

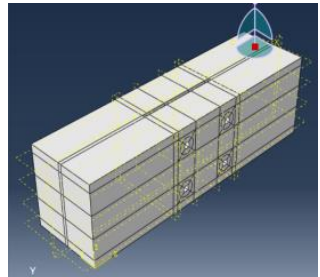

(e)

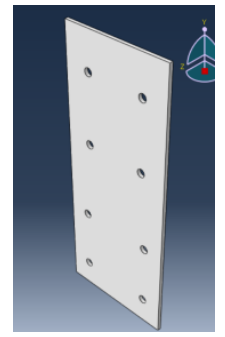

(f)

Figure 6. (a) beam bolts (Length: $150 \mathrm{~mm})$; (b) column bolts (Length: $292 \mathrm{~mm})$; (c) beam $(830 \mathrm{~mm} \times 130 \mathrm{~mm} \times 305 \mathrm{~mm})$; (d) nut (Radius: $15 \mathrm{~mm}$ Thickness: $10 \mathrm{~mm})$; (e) column $(1000 \mathrm{~mm} \times 272 \mathrm{~mm} \times 305 \mathrm{~mm})$; (f) steel plate $(9.5 \mathrm{~mm} \times 305 \mathrm{~mm} \times 745 \mathrm{~mm})$.

The elastic performance of the bolted timber joints is usually decided by the embedment strength of glulam material. To consider the ductile performance at the local level, a common approach is to weaken the elastic modulus near the pre-drilled holes on the glulam elements. The elastic property and other properties of materials are summarized in Tables 1 to 5 .

Table 1. Isotropic steel material properties specified for steel bolts.

\begin{tabular}{|c|c|c|c|c|c|}
\hline \multicolumn{3}{|c|}{ Elastic } & & \multicolumn{2}{|c|}{ Plastic } \\
\hline & Young's & Poisson's Ratio & & Yield & Plast \\
\hline & Modulus & & & Stress & Strai \\
\hline \multirow[t]{3}{*}{1} & 200000 & 0.3 & 1 & 640 & 0 \\
\hline & & & 2 & 640 & 2 \\
\hline & \multicolumn{2}{|c|}{ Young's Modulus } & \multicolumn{3}{|c|}{ Poisson's Ratio } \\
\hline & \multicolumn{2}{|c|}{200000} & & 0.3 & \\
\hline
\end{tabular}

Table 2. Isotropic behavior of steel plates.

Elastic isotropic behavior

Young's Modulus

Poisson's Ratio

Plastic isotropic behavior
Plastic isotropic Plastic Strain ${ }^{H_{n s}}$

200000

$$
0.3
$$

$\begin{array}{ll}1 & 390 \\ 2 & 390\end{array}$

Table 3. Wood foundation potential isotropic plastic behavior.

\begin{tabular}{ccc}
\hline \multicolumn{3}{c}{ Isotropic plastic behavior } \\
\hline & Yield Stress & Plastic Strain \\
1 & 20.85 & 0 \\
2 & 20.85 & 2 \\
\hline
\end{tabular}

Table 4. Timber elastic engineering constants.

\begin{tabular}{|c|c|c|c|c|}
\hline \multicolumn{5}{|c|}{ Elastic Engineering Constants } \\
\hline $\mathrm{E}_{1}$ & $\mathrm{E}_{2}$ & $\mathrm{E}_{3}$ & $\mathrm{Nu}_{12}$ & $\mathrm{Nu}_{13}$ \\
\hline 12000 & 500 & 500 & 0.35 & 0.35 \\
\hline $\mathrm{Nu}_{23}$ & $\mathrm{G}_{12}$ & $\mathrm{G}_{13}$ & $\mathrm{G}_{23}$ & \\
\hline 0.4 & 600 & 600 & 600 & \\
\hline \multicolumn{5}{|c|}{ Isotropic plastic behavior is: } \\
\hline & \multicolumn{2}{|c|}{ Yield Stress } & \multicolumn{2}{|c|}{ Plastic Strain } \\
\hline 1 & \multicolumn{2}{|c|}{35} & \multicolumn{2}{|c|}{0} \\
\hline 2 & \multicolumn{2}{|c|}{35} & \multicolumn{2}{|c|}{2} \\
\hline
\end{tabular}

\subsection{Specific parameters of model}

Table 5. Specific parameters of model.

\begin{tabular}{|c|c|c|}
\hline Variable & Explanation & Value \\
\hline Layer & The Number of fasteners on the layer & 2 \\
\hline Column & The Number of fasteners on columns & 2 \\
\hline$E_{D}$ & The End Distance (Distance from fastener to the post) & $120 \mathrm{~mm}$ \\
\hline$V_{D}$ & The Vertical distance & $85 \mathrm{~mm} 110 \mathrm{~mm} 85 \mathrm{~mm}$ \\
\hline$H_{D}$ & The Horizontal Distance & $105 \mathrm{~mm}$ \\
\hline$B_{s e c}$ & The Width of the section & $180 \mathrm{~mm}$ \\
\hline$t_{\text {steel }}$ & The Thickness of steel member & $12 \mathrm{~mm}$ \\
\hline G & Specific gravity & $400 \mathrm{~kg} / \mathrm{m}^{3}$ \\
\hline$d$ & Diameter of the bolts & $20 \mathrm{~mm}$ \\
\hline$b h_{2}$ & Flutes pitch of the bolts & $2.5 \mathrm{~mm}$ \\
\hline$f_{t}$ & Tensile strength & $600 \mathrm{~N} / \mathrm{mm}^{2}$ \\
\hline$f_{c, \perp}$ & Compression strength perpendicular to the grain & $2.5 \mathrm{~N} / \mathrm{mm}^{2}$ \\
\hline$f_{c, / /}$ & Compression strength parallel to the grain & $10 \mathrm{~N} / \mathrm{mm}^{2}$ \\
\hline$\rho$ & Density of wood & $399 \mathrm{~kg} / \mathrm{m}^{3}$ \\
\hline$k$ & $\bmod$ & 0.8 \\
\hline$\gamma$ & $\bmod$ & 1.25 \\
\hline$H_{s t}$ & Size of the pre-drilled holes on the side timber elements & $22 \mathrm{~mm}$ \\
\hline $\operatorname{ain}_{m s}^{H_{m s}}$ & Size of the pre-drilled holes on the middle steel elements & $22 \mathrm{~mm}$ \\
\hline$d_{B C}$ & Gap length between the beam and the column & $3 \mathrm{~mm}$ \\
\hline$f_{e, 0}$ & Embedment Strength parallel to the grain, unit in $\mathrm{MPa}$ & Need to be calculated \\
\hline$f_{e, 90}$ & Embedment Strength perpendicular to the grain, unit in $\mathrm{MPa}$ & Need to be calculated \\
\hline$M_{u}$ & Ultimate moment capacity of bolted joint, unit in $\mathrm{kN}^{\prime} \mathrm{m}$ & \\
\hline$H_{\text {load }}$ & How far the applied load to the rotational center is. & $1337.5 \mathrm{~mm}$ \\
\hline
\end{tabular}

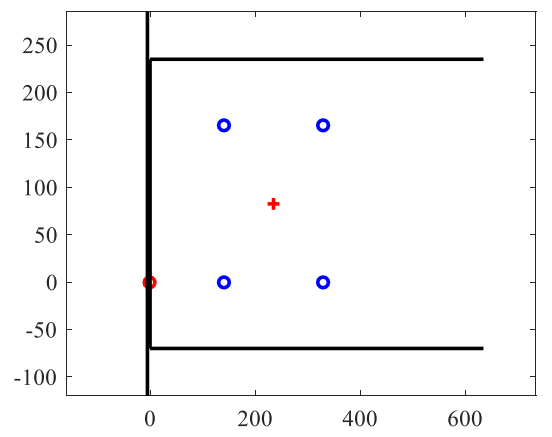

Figure 7. Fasteners of connection in Matlab.

\subsection{Definition of yield from moment-rotation curve}

The yield point of a system (the red dot on line in Figure 7) is usually defined as a point on a hysteretic or monotonic backbone curve where plastic deformation begins. For the timber structural elements, however, the nonlinearity often 
occurs at an earlier stage. Consequently, a normal yield point is commonly defined on a monotonic pushover curve.

\subsection{Simulation results}

All model parts were loaded until they were fully damaged. The damage condition is shown below. With the created
FEM, the numerical model was created and the result was got. Assuming the ductile performance of the element, the shear strength of a bolted connection is highly influenced by the embedment strength of wood. The Stress distribution of the deformed specimen is presented in Figure 8.

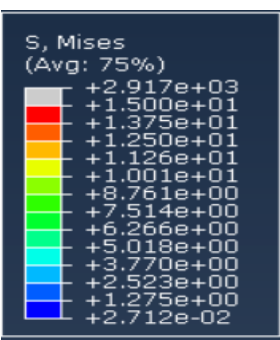

(a)

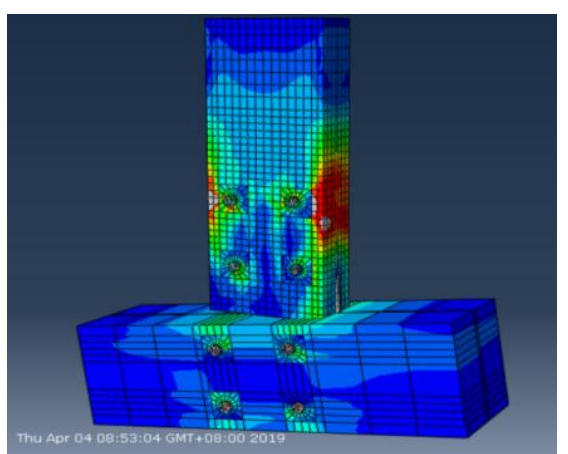

(b)

Figure 8. (a) Stress; (b) Stress distribution of the deformed specimen.

Shown from the above study, some assumptions were made according to some preliminary estimation of the moment carrying capacities for a type of timber-timber joints (shown in Figure 9(a)). The shear and rotational analyses were presented in the figure.

Assumption:

(1) The center of rotation is the geometric centroid of the fasteners;

(2) The deformations within the timber elements are small such that the relative locations of the holes do not change;

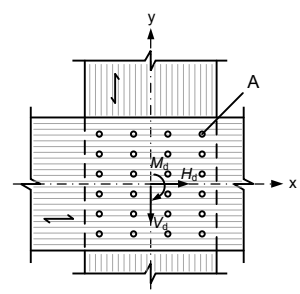

(a)

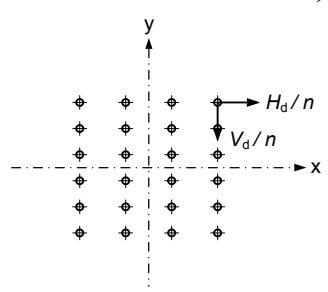

(b)

(3) The column element and the steel plates suffer no damage;

(4) The shear force is evenly resisted by all the n fasteners (shown in Figure 9(b)). That is, the horizontal shear $\mathrm{F}_{\mathrm{h}, \mathrm{d}}=\mathrm{H}_{\mathrm{d} / \mathrm{n}}$, and the vertical shear $\mathrm{F}_{\mathrm{v}, \mathrm{d}}=\mathrm{V}_{\mathrm{d} / \mathrm{n}}$;

(5) The rotational strength is dominated by the shear capacity perpendicular to the moment arm of each fastener Fm,d), whose direction is perpendicular to the line between the fastener and the geometric centroid (shown in Figure $9(\mathrm{c}))$;

(6) The dowel load is the vector addition of three forces, i.e. Fm,d, Fh,d, and Fv,d.

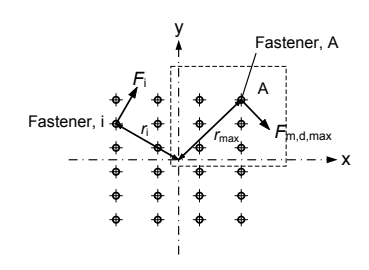

(c)

Figure 9. Load carrying capacities of bolted timber joints (a) simplified timber-timber joint; (b) shear resistance; (c) moment resistance.

\section{Hand calculation}

\subsection{Embedment strength calculation}

The elastic performance of the bolted timber joints is usually decided by the embedment strength of glulam. The strength of multiple fastener connections does not equal the strength of the single fastener connection multiplied by the number of fasteners. Generally, the connection fails at a lower load because the timber splits or because the wood is softened, which can be explained by the complicated stress distribution around the fastener position. For this case, the initial embedment strength ( $\mathrm{ES}_{0}$, in the unit of MPA) is expressed by Eq. (1). The result is 32.79MPA.

$$
\begin{aligned}
& E S_{0}=0.082 \times \rho_{k} \times\left(1-0.01 \times b \mathrm{~h}_{1}\right) \\
& =0.082 \times 400 \mathrm{~kg} / \mathrm{m}^{3} \times(1-0.01 \times 0.02 \mathrm{~m})
\end{aligned}
$$

The coefficient compression of wood is then calculated following Eq. (2).

$K_{90}=1.35+0.15 \times 0.02 \mathrm{~m}=1.353$

To calculate the sum of the total embedment strength after, a series of formula called Eurocode need to be used. Eq. (3) $-(6)$

Following Eurocode

$f_{e, 0}=0.082(1-0.01 \mathrm{~d}) \rho_{\mathrm{k}}$ 
$f_{e, 90}=\frac{f_{e, 0}}{k_{90}}$

$f_{e, \theta}=\frac{f_{e, 0}}{k_{90} \sin ^{2} \theta+\cos ^{2} \theta}$

$k_{90}=1.35+0.015 d$

\subsection{Estimation of shear and rotational strength}

The ultimate moment $\left(\mathrm{M}_{\mathrm{u}}\right)$ capacity or shear force is also an important attribute to determine the moment resistance of timber structure. $\mathrm{M}_{\mathrm{u}}$ is influenced by the compression strength $\left(\mathrm{f}_{\mathrm{c}, / /}\right)$ parallel to the grain. $\mathrm{f}_{\mathrm{c}, / /}$ is linear when the deformation is small, and it reaches a cap when deformation becomes larger, which is shown in Figure 11.

The $\mathrm{i}^{\text {th }}$ bolt is angled $\theta_{\mathrm{i}}$ from the grain and has a distance of $r_{i}$ from the rotation center. Shown from the Figure 7, bolt \# 1 in this case has the longest distance from the rotation center, which is the red dot on the line. Thus, it can be assumed that when the joint reaches its capacity, bolt \# 1 has the largest shear force out of all the bolts, and the shear force of the $i^{\text {th }}$ bolt could be assumed to have a linear correlation with Eq. 7.

$F_{M, i}=\frac{r_{i}}{r_{1}} F_{M, 1}$

while calculating $\mathrm{M}_{\mathrm{u}}$, a check needs to be done to make sure that bolt \# 1 has largest shear stress. Then, the design ultimate moment resisting capacity of the joint with $\mathrm{n}$ bolts is expressed in Eq. 8 to 11 .

$M_{b}=\sum_{i=1}^{n} r_{i} F_{M, i}$

$F_{c}=\sum_{i=1}^{n} F_{M, i} \cos \theta_{i}$

$M_{c}=\left\{\begin{array}{c}\frac{2 F_{c} h_{1}}{3} \\ \text { when } F_{c} \leq \frac{f_{c, / l} b h_{1}}{2} \\ f_{c, / /} b h_{1}^{2}\left(\beta-\frac{\beta^{2}}{2}\right)+\frac{f_{c, / /} b h_{1}^{2}(1-\beta)^{2}}{3} \\ \text { when } \frac{f_{c, / /} b h_{1}}{2}<F_{c} \leq f_{c, / /} b h_{1}, \beta=\frac{2 F_{c}}{f_{c, / /} b h_{1}}-1\end{array}\right.$

$M_{\mathrm{u}}=M_{b}+M_{c}$

The shear force may have different effect on the timber model if the angle of the force is applied differently. The rotation center will also determine the effect of shear force. The following study simulated some hypothesized cases when timber structure joints under different shear force.

For the cases when the joints were under pure shear, the shear force is equally resisted by all the bolts (as shown in Figure 10(a)). For the cases when the joint is under a pure bending moment, a portion of the beam might touch and squeeze the column surface. This type of case is shown in Figure $8(\mathrm{~b})$. For most of the cases, the shear force and the moment are coupled together, which is shown in Figure 8(c)) [1].

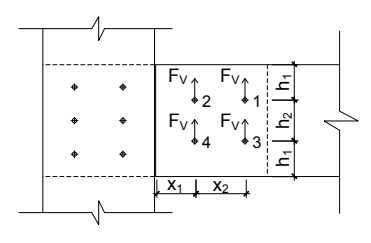

(a)

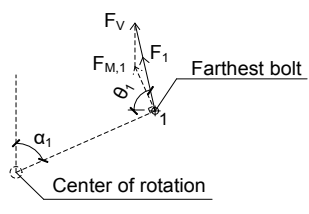

Center of rotation

Figure 10. Internal forces of bolted timber joints (a) pure shear; (b) pure bending moment; (c) coupled shear and bending moment.

The hand simulation result was made in Matlab, and the graph was presented in Figure 11.
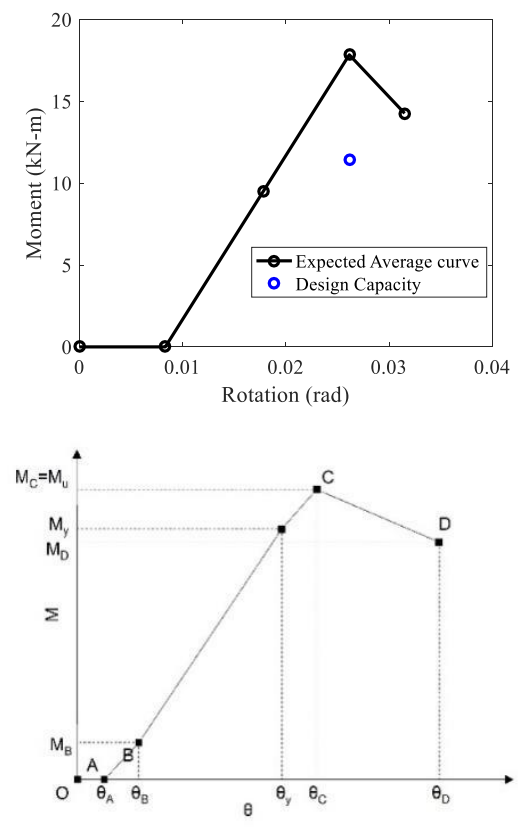

Figure 11. Key points defining the estimated moment-rotation curves for the bolted timber joint.

\subsection{Compare and analysis}

The FEM simulated result and the hand calculated result of the prototype bolted joint were compared. Shown in Figure 12 .

When rotation occurs from rad 0 to $\mathrm{rad} 0.9$, there is no moment resistance for both the Abaqus model and hand-calculation model. This is because the size of the pre-drilled hole is larger than the diameter of the fastener, which creates a small gap between the hole and the timber. In this gap, the rotation of structure will not result in moment resistance because there is no contact, which creates the initial horizontal line.

When timber contact with the surface of the fastener, an increase in moment resistance occurs in both models. Because the stiffness and strength of both models are 
approximately the same, the increase slope and value are almost the same.

On rad 0.026 (1.49 degree), a slip occurs on the hand-calculation model. This is because the hand-calculation model considered the split of the wood, and the joint is broken, which means ductile. This joint is plastic. The ideal ductility means that the joint still works when the split is over 3\%.

There might be two reasons for the plasticity of timber:

1.The large size of fastener. The fasteners take over the most part of the surface, which makes the hole large. As a result of that, the timber is easier to split.

2 . The diameter of cross-section is small, only $130 \mathrm{~mm}$. $130 \mathrm{~mm}$ is not enough for a normal beam in the real construction.

While in the FEM model, because the split of timber was not defined initially, the strength did not have an obvious reduction, shown in graph 12 .

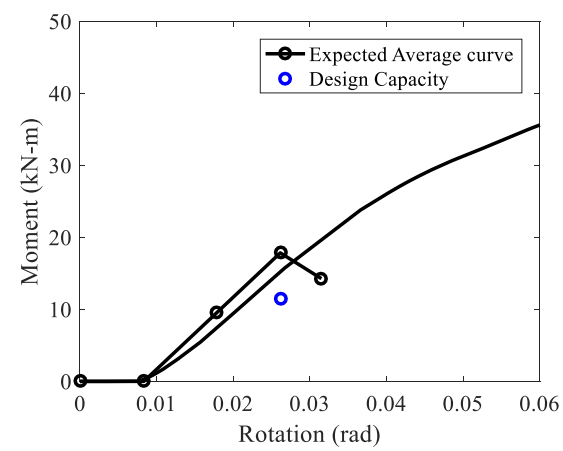

Figure 12. Hand calculation model vs. Abaqus FEM model.

On $\mathrm{rad} 0.026$ to 0.033 , the hand calculation model estimates that the plastic deformation will occur, and moment starts to reduce. The hand-calculating graph stopped at radian 0.033 , because after 0.033 , the hand calculation model considers the joint not hold any moment resistance, which means it is broken totally.

Parametric Design:

Parametric design can be applied in Matlab with the hand-calculation equations, which would help to analyze which type of connection is more suitable in real-world construction.

1.Change fasteners

Besides $2 \times 2$, more fasteners could be added to the joints. Accordingly, the diameter of the fastener was changed smaller in order to adjust the new joint. $2 \times 2,2 \times 3,3 \times 2$, were made in Matlab, and the graphs were given in Figure 13.

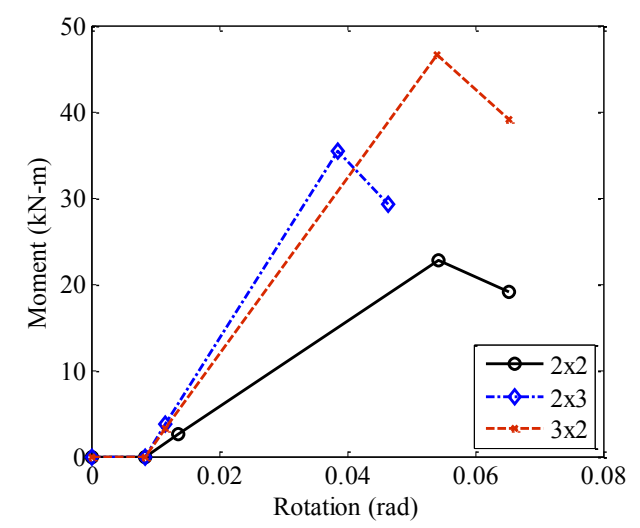

Figure 13. Moment-Rotation graphs of connections with different fasteners.

2. Change column width

Once the width changed, the moment resistance of the connection changed significantly. Its ductility bond doubled, as the width of the column doubled, which is shown in Figure14.

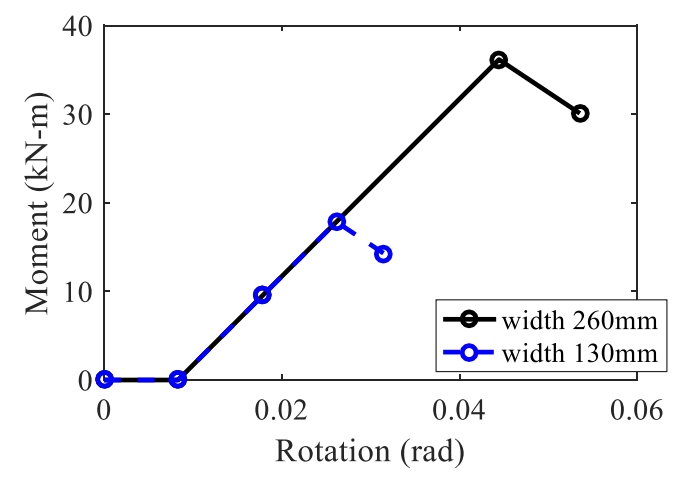

Figure 14. The change in width of column section.

\section{Change fastener diameters}

The large size of fastener provides more moment resistance to the connection. However, it also makes the timber easier to split. According to Figure 15, the increased size of fastener brings more moment resistance, but also makes the ductile performance occur more easily in less rotational radians.

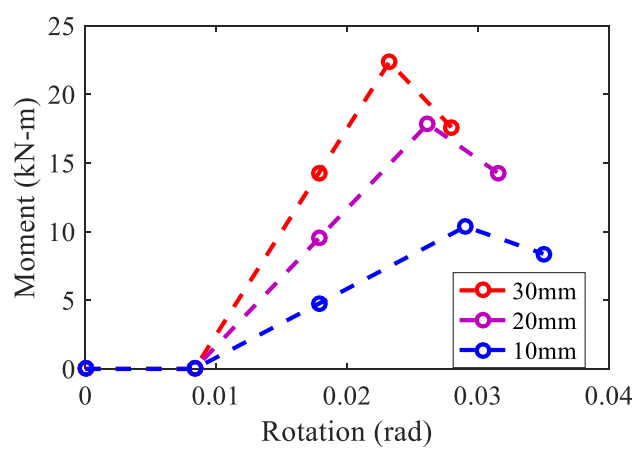

Figure 15. The change in diameter of fastener.

\section{Conclusions and future work}

To comprehend the moment resistance of glulam bolted 
timber connections. A finite element model was first established in Abaqus. Furthermore, a hand calculation method for such types of joints was implemented in Matlab. Comparisons between the Abaqus model and the hand-calculation model were provided. Finally, a parametric study was carried out, which proves the defects of large fasteners and the advantages of using more fasteners with large width cross-sections. The presented work leads to the following conclusions:

(1) The hand calculation provided considered many practical factors. The Abaqus model, in comparison, did not achieve the goal of properly and realistically simulating the slotted-in bolted connection of glulam timber. The calculated results could be directly used to model the performance of the bolted joints. Furthermore, the designers could use the hand calculation to obtain the moment-rotation curve for any slotted-in glulam timber connections.

(2) It was found that the number of fasteners in the row and column, the width of the column, the diameter of the fastener, and the gap between the pre-drilled hole and the fastener are all important parameters to affect the moment-rad performance of the slotted-in bolted connection. The increased number of fasteners could significantly increase the moment resistance of the connection. The width of column section is in proper ratio with both the strength and ductile performance of the connection. The large size of fastener leads to better rotational strength, but also makes the connection more brittle, indicating early cracks to occur.

In addition, some assumptions could be elaborated in the future:

The resistance of bolted joints connection to rotational force is not strong enough. The model in this study is adopted from real-world connection. Improvements need to be provided in the future regarding to this type of connection. Although increasing the number of fasteners could largely increase the strength of the connection, new connection type is desired to be invented in the future to provide stable and ductile rotational resistances.

\section{Acknowledgment}

The results of this work is partially based on the earlier work done in Tongji University (Prof. He, Minjuan and Dr. Li Zheng). The authors gratefully acknowledge Ms. Yuan, and all her colleagues from Illume Research program, who helped to make this report real. The author would also appreciate the support from Guo, Junting's mother and Prof. Shu's family members who greatly supported this work.

\section{Reference}

1. Z. Shu, Z. Li, X. Yu et al., Rotational performance of glulam bolted joints: Experimental investigation and analytical approach, Construction and Building Materials, https://doi.org/10.1016/j.conbuildmat.2019.03.002

2. Designing Buildings Wiki Share your construction industry knowledge www.designingbuildings.co.uk. (n.d.). Retrieved from https://www.designingbui ldings.co.uk/wiki/Advantages_and_disadvantages_of_t imber_frame_buildings

3. Tokyo to build world's tallest timber tower. (2018, February 20). Retrieved from https://www.cnn.com/style/article/wooden-skyscraperstimber-trend-catching-fire-duplicate-2/index.html

4. Block, I. (2019, March 21). Mjøstårnet in Norway becomes world's tallest timber tower. Retrieved from https://www.dezeen.com/

2019/03/19/mjostarne-worlds-tallest-timber-tower-vollarkitekter-norway/

5. Custódio, J., Broughton, J., \& Cruz, H. (2009). A review of factors influencing the durability of structural bonded timber joints. International Journal of Adhesion and Adhesives, 29(2), 173-185. doi:10.1016/j.ijadhadh.2008.03.002

6. Top 5: The World's Tallest Timber Buildings. (n.d.). Retrieved from https://www.theb1m.com/video/top-5-the-world-s-talle st-timber-buildings

7. OBE, J. D. (2002). Timber its nature and behaviour. Hoboken: Taylor and Francis.

8. 2012 International Building Code. Country Club Hills, Ill: ICC. 2011. p. 36. ISBN 1609830407.GWEC. Global Wind 2017 Report. http://files.gwec.net/files/GWR2017.pdf; 2018.

9. https://commons.wikimedia.org/wiki/File:Parallam_Par allel_strand_lumber.jpg (Free License)

10. https://commons.wikimedia.org/wiki/File:Линия сращивания и зарезки шипового соединения клееного бруса. Сокольский ДОК, Россия

11. Elke Wetzig (elya) - Own work, CC BY-SA 3.0, https://commons.wikimedia.org/w/index.php?curid=83 83391

12. https://commons.wikimedia.org/wiki/File:Laminated_V eneer_Lumber.png (Free License)

13. Andreolli, M., Tomasi R., Piazza M., Zandonini R. (2011). Ductile moment-resistant steel-timber connections. Ice|proceedings

14. Steinhardt, Nancy W. (2002). Chinese Architecture (English ed.). Yale University Press. p. 1. ISBN 978-0-300-09559-3.Liu X, Lu C, Li G, Godbole A, Chen Y. Effects of aerodynamic damping on the tower load of offshore horizontal axis wind turbines. Appl Energy 2020;204:1101-14.

15. Bob Vila. (2016, November 15). How to Make a Mortise and Tenon Joint. Retrieved from https://www.bobvila.com/articles/2138-how-to-make-a -mortise-and-tenon-joint/

16. Komatsu, K. (2017). Development of stiffer and ductile glulam portal frame. doi:10.1063/1.5011506

17. Iqbal, A., Pampanin, S., \& Buchanan, A. H. (2015). Seismic Performance of Full-Scale Post-Tensioned Timber Beam-Column Connections. Journal of Earthquake Engineering, 20(3), 383-405. doi:10.1080/13632469.2015.1070386

18. Ataei, Abdolreza \& Bradford, Mark \& Valipour, Hamid \& A. Chiniforush, Alireza. (2018). EXTENDED END 
PLATE SEMI-RIGID COMPOSITE JOINTS WITH CLT PANELS AND DEMOUNTABLE SHEAR CONNECTROS.

19. Moses, D. M., \& Prion, H. G. (2003). A three-dimensional model for bolted connections in wood. Canadian Journal of Civil Engineering, 30(3), 555-567. doi:10.1139/103-009

20. Cesare, A. D., Ponzo, F. C., Pampanin, S., Smith, T., Nigro, D., \& Lamarucciola, N. (2019). Displacement based design of post-tensioned timber framed buildings with dissipative rocking mechanism. Soil Dynamics and Earthquake Engineering, 116, 317-330. doi:10.1016/j.soildyn.2018.10.019

21. J.P. Hong, D.Barrett, Three-dimensional finite-element modeling of nailed connections in wood, J. Struct. Eng. 136(6)(2010)715-722.

22. Daryl L. Logan (2011). A first course in the finite element method. Cengage Learning. ISBN 978-0495668251.

23. Andre Jorissen (1999). Double shear timber connections with dowel type fasteners. HERON. ISSN 0046-7316. 